https://doi.org/10.31713/m1026

\title{
MOBILE AUTONOMOUS DUST-REMOVAL INSTALLATION
}

\author{
Victor Shapovalov ${ }^{\text {a* }}$ \\ ${ }^{a}$ Department of Labor Protection and Civil Safety, \\ Kryvyi Rih National University, Kryvyi Rih, Ukraine
}

*Corresponding author Victor Shapovalov, email: vash231@meta.ua

The aim of this work is to solve the actual problem of dust removal in industrial shops of processing enterprises. Technological processes for the bulk materials processing are accompanied by intense dust emission, as a result of which the air dustiness at workplaces considerably exceeds the maximum permissible values. Known methods of dust suppression do not fully localize numerous sources of dust emission. The released dust spreads over the entire volume of the production area and is deposited on various surfaces and forms the layers of different thickness. Under the influence of various factors, the settled dust can again become aerosol, which in turn, increases the air dustiness in the workplace, which may contribute to the emergence of occupational diseases among workers in processing plants. To prevent secondary dust emission and cleaning of various surfaces from the settled dust, the mobile autonomous dust-removal installation, which can autonomously move to the necessary cleaning object within the limits of the given enterprise, has been developed.

Keywords: dust emission, dust removal, dust removal installation, pipeline system

\section{Introduction}

Most industrial enterprises, which use bulk materials are forced to solve the problem associated with the release of dust and its removal. Technological processes for the bulk materials processing (crushing, sorting, reloading, etc.) are accompanied by intense dust emission, as a result of which the air dustiness at workplaces considerably exceeds the maximum permissible values. The most promising ways of dust emissions prevention are the improvement of technological processes and the introduction of waste-free energy-saving technologies. However, for most enterprises, the introduction of such technologies is not always technologically possible or economically feasible. Known methods of dust suppression, such as aspiration, room ventilation, dust binding by moistening the processed material, sealing of the transfer points, etc., do not fully localize numerous sources of dust emission [1-3]. The released dust spreads over the entire volume of the production area and is deposited on various 
surfaces (building structures, pipelines, cable lines, elements of equipment, etc.), and forms the layers of different thickness. Under the influence of various factors (the operation of the technological equipment, vibration created by equipment, the movement of the bridge cranes, the production of repair works, the presence of aeration streams, etc.), the settled dust can again become aerosol. This increases the air dustiness in the workplace, which may contribute to the emergence of occupational diseases among workers in processing plants.

At the same time, the dust accumulated on various surfaces complicates the maintenance and repair of technological equipment and communications, accelerates the wear of individual units and parts, reduces the time needed for overhaul maintenance, disables control and measuring equipment and weighing equipment. In a number of industries, the settled dust causes explosions or fires [4,5]. For many enterprises (woodworking, cement, for the production of dry building mixtures, sintering, foundry, etc.), the dust settled on various surfaces is considered as a valuable resource in solving problems of energy saving and energy efficiency, due to utilization and recycling $[3,6,7]$.

Therefore, for most industrial enterprises, which use bulk materials, dust removal is an urgent problem, the solution of which allows to improve working conditions, reduce occupational diseases, reduce equipment wear, and reduce the amount of waste due to disposal of the collected material.

To prevent secondary dust emission and cleaning of various surfaces from the settled dust, pneumatic dust-collecting installations are used, which have found wide application in various industries. There are portable, mobile and stationary dust-collecting installations depending on the performance of the main equipment and the length of the pipelines.

\section{Materials and methods}

The bulk raw material processing technologies are characterized by an abundance of intensive dust extraction sources and significant areas of dust deposits, which are subjected to dust removal. The most effective way of dust removal for such conditions is the use of 
centralized dust collectors (CDC) or industrial stationary vacuum systems [8].

In the works of most authors, there was a positive experience of using the CDC in industrial conditions [9-12]. Cleaning of industrial premises using the $\mathrm{CDC}$ provides productive cleaning of surfaces using several dust-removal nozzles simultaneously, a high degree of cleaning in dust-collecting devices and convenient unloading of the collected material, removal of dust deposits from various surfaces located at different heights. The $\mathrm{CDC}$ has a high sanitary and hygienic efficiency since all the dust is removed from the premises. The considerable length of the pipeline system of the CDC allows the use of such installations in premises with a large accumulation of process equipment. At the same time, the thrust booster and dust collection devices may be located outside the cleaned premises.

Operating experience of the CDC showed their prospects, therefore, they were developed in various industrial sectors. Thus, the CDC is used in the textile and printing industries, in the shops of crushed stone and engineering plants, railway transport enterprises and other industrial enterprises [8,10-12].

However, it should be noted that CDCs are mounted permanently and fitted for cleaning only one room. The stationary pipeline system, during long-term operation, is prone to clogging and requires cleaning or dismantling. Due to dust deposits in the pipelines, the amount of air pumped through the dust nozzles is significantly reduced, as a result of which the aerodynamic parameters and the overall performance of the vacuum system change.

Technological processes for the processing of bulk materials include the use of a large number of main and auxiliary equipment. The considerable length of pipelines of stationary vacuum systems is due to the significant areas for cleaning, as well as a significant amount of equipment located in these areas. Therefore, in the working conditions of processing plants, it is necessary to use several CDCs or several separately installed stationary pipeline systems. The significant length of pipelines may contribute to the disruption of the stable operation of the vacuum system and includes the selection of high-performance thrust boosters, which consume large amounts of electricity. 
Along with stationary installed main equipment, the attempts to use the CDC with equipment mounted on a mobile base were made [7]. In this case, the pipeline system is mounted stationary, and the main equipment, which is mounted on the cart, moves through the shop and alternately connects to the risers. The main disadvantages of this modification are lack of the main equipment manoeuvrability, due to the large dimensions; returning the air cleaned in dustcollecting devices back to the room, which is not recommended in highly dusty premises.

Thus, the most significant disadvantage of all modifications of the CDC is a stationary mounted pipeline system of considerable length. It should also be noted that one installation serves one production facility. For large enterprises, it is necessary to use several installations of the same type, each of which will have a stationary installed pipeline system. This complicates the control of pipelines clogging and is associated with an increase in maintenance costs and service of an extended pipeline system within one enterprise.

The accumulation of dust on the surfaces of industrial buildings and equipment is not the same. The amount of dust and the intensity of its deposition on surfaces located in the upper part of the production area is significantly less than at the dust sources. Therefore, the frequency of pneumatic dust removal in each separately taken room will depend on the intensity of deposition and accumulation of dust on the elements of this object. This will allow enterprises to "keep clean" production facilities using a mobile autonomous dust-removal installation (MADRI), which after cleaning a single object, can move to the next object, etc.

\section{Results}

The design of the MADRI uses standard typical units of aspiration and dust collection systems. The scheme of MADRI is presented in Fig.1. 


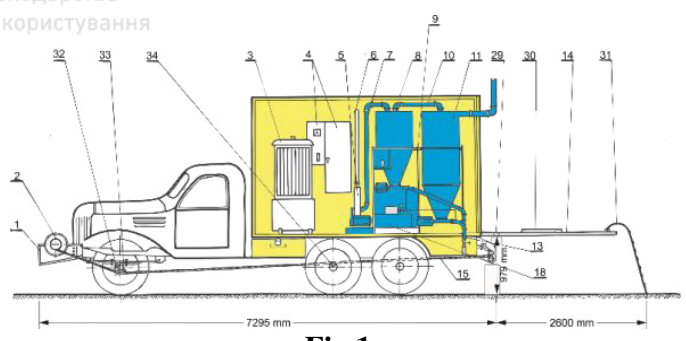

Fig.1a
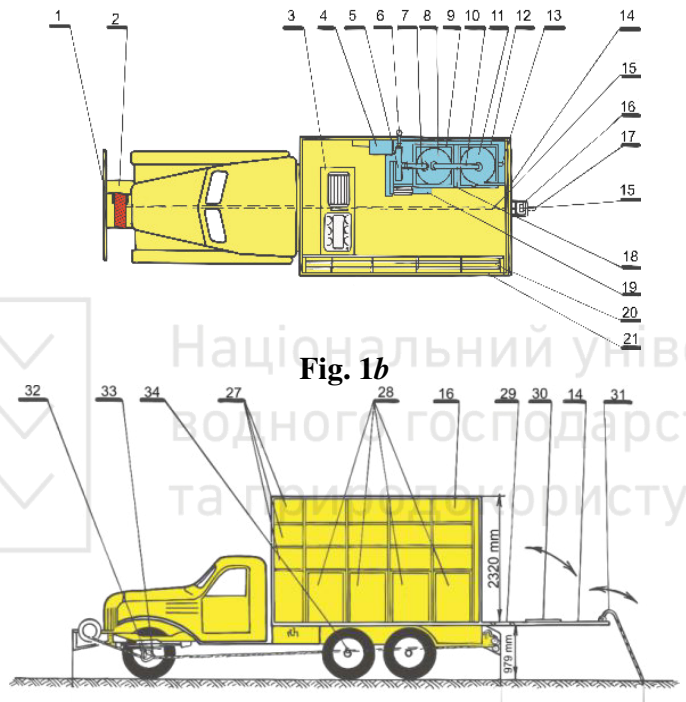

Fig. 1c

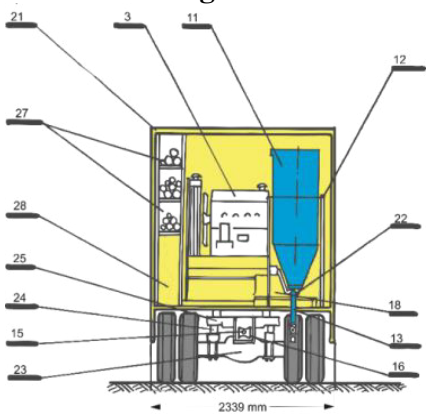

Fig. 1d

Fig. 1. Scheme of mobile autonomous dust removal installation 
The main equipment of the MADRI is located in the back of a cargo van. Dust collecting devices are presented in the form of a two-stage cleaning system consisting of a cyclone 11 and a fabric filter 8 . The cyclone and the filter are mounted on the support frames 12 and 9, respectively, and interconnected by a pipeline 10 .

An air baghouse and a cyclone have discharge pressing installations 22 interconnected by a pipeline system with a lock-up valve 13. This allows the discharge of collected dust using a screw discharge device. A binder liquid (humidifier) is fed to the pressing devices from the tank 18, in order to prevent dust emission during the dust discharge.

The vacuum in the system is provided by the thrust booster 5 , which pulls the dusty air through the dust collecting device and connected with it by a pipeline 7 . Turning on and off the thrust booster is carried out using the control box 19. The purified air is released into the environment through pipe 6 , which is brought out through the wall of the cargo body. The MADRI is supplied with electricity by means of a diesel generator 3 , controlled by an electric switchboard 4 .

In the cargo body, in addition to the main equipment, there are racks 27 for storing the required number of pipes of different diameters and fittings (pipe branches, tee-joints, etc.), as well as ladders and stepladders. Under the racks, there are boxes 28 for storing equipment and inventory (clamps, carabiners, ropes, nozzles, handles, etc.).

In the front part of the van, which protected by a buffer frame 1, there is a winch truck 2 , on the drum of which a cable 15 is wound. The cable is laid under the bottom of the van through the front bypass roller 32 , the intermediate bypass roller 34 and trough the rear bypass rollers 16. The front bypass roller is mounted on the front bridge girder of the van using a clamp 33 (Fig. 1c).

Assembling the pipeline vertical section, as well as the supply of fittings and elements of the pipeline horizontal section at a given height of the building, is carried out using a winch truck. The vertical section of the pipeline is located outside or inside the building (for example, a mounting aperture) and is also mounted as a horizontal section, but only for the period of premises cleaning.

The rear part of cargo body is covered with mounting plate 14. In working condition, the mounting plate is in a horizontal position, with the possibility of vertical movement and serves as a platform for conducting the installation works of the pipeline vertical section. The 
opening 29 for passing the cable of the winch truck is located at the bottom of the shield. After work, the opening is closed by a cover 30 . The mounting plate is also equipped with a folding ladder 31 .

MADRI is serviced by three people, one of which is simultaneously a driver and MADRI operator, and two others are dust collectors. The MADRI operator controls the operation of the main equipment, and the dust collectors clean the premises, moreover, the cleaning of high-level surfaces and hard-to-reach places is carried out by two dust collectors. The first dust collector cleans up the high-level surfaces, and the second ensures the operator working on the stepladder, and also switches the flexible hose from one nozzle to another, supplies the necessary nozzles, etc.

Before starting the MADRI, it is necessary to perform installation work connected with the installation of vertical and horizontal sections of the pipeline. Since the dust removal installation is autonomous and mobile, this type of installation work will be carried out continuously when it is moved to a new place of cleaning. Before assembling the vertical section of the pipeline, the van is located near the building in the place where the pipeline system will be supplied into the premises at a given mark (Fig. 2).

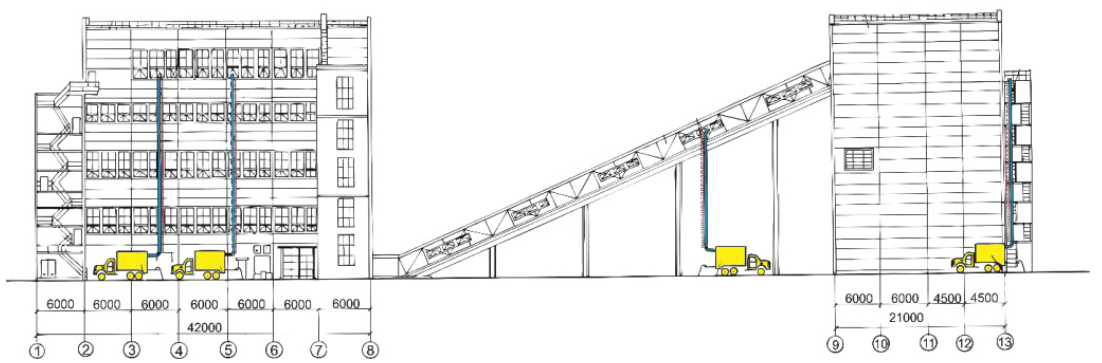

Fig.2. Location of MADRI in the process of the pipeline vertical section assembly

An important element of the equipment, which is required for installation work is a block clamp (Fig. 3). 


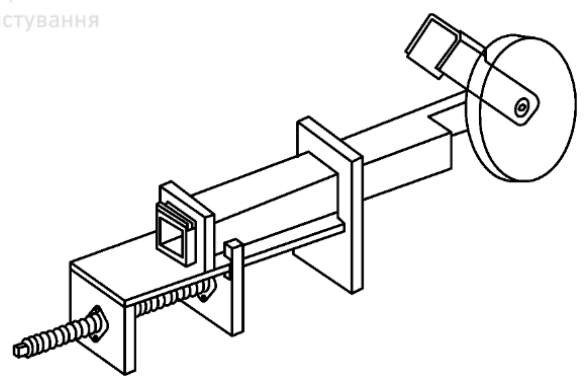

Fig. 3. Block clamp

The block clamp is used for mounting the vertical section of pipelines. One of the operators select a place for the pipeline vertical section, secures the clamp and passes the cable of the winch truck through the bypass roller. As a selected place for a clamp mounting, there can be mounting or window openings at a given elevation of a building, through which the piping system will be supplied into the premises (Fig. 2).

The rings are fixed over a certain distance on the winch truck cable. The pipe sections of the vertical section are mounted on these rings using carbines. The connection of two pieces of the pipe is made using a ring clamp (Fig. 4).

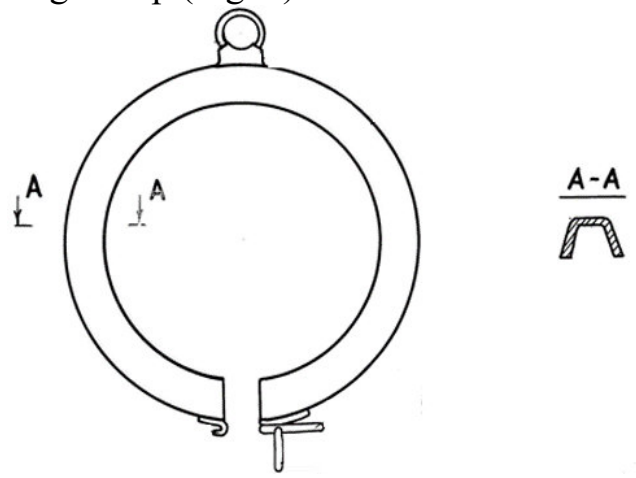

Fig. 4. Ring clamp

The ring on the clamp (Fig. 4) serves to hang the pipes on the winch truck cable, and then the pipeline is lifted to the required height, with gradually increasing of the pipeline length (height). In case of discrepancy between the rings fixed on the cable and on the 
clamps, then the additional floating clamps are installed for hanging the pipes, the diameter of which is equal to the pipeline outer diameter. Two pieces of pipe are joint to each other by the ends, and then the clamp is put on and locked with a bracket (Fig. 5).

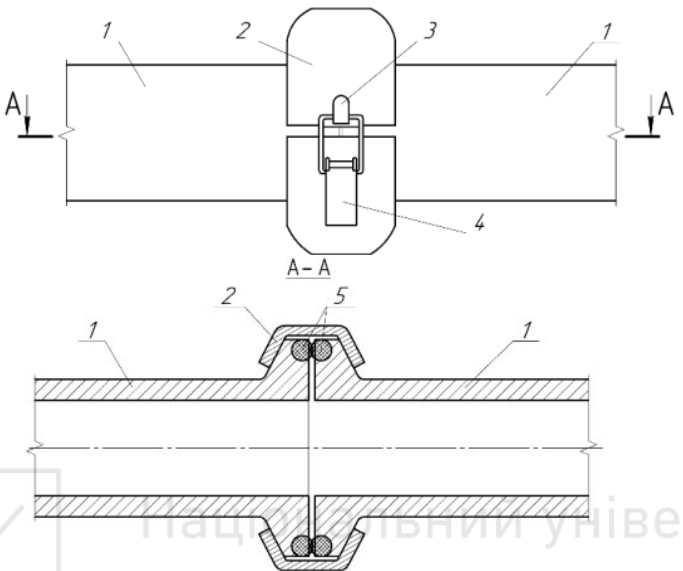

Fig. 5. Joint of two pipe sections: 1 - pipe sections; 2 - ring clamp; 3 - hook; 4 locking bracket; 5 - rubber sealing rings

The cross-section of the ring clamp has the shape of a truncated trapezoid (Fig. 4), while the cross-section of the pipe ends when joining has the shape of rectangular truncated triangles, in which rubber sealing rings are inserted (Fig. 5). This solution of two pipe sections joining eliminates air inflow, provides tightness and rigidity of the mounted section, allows quick and efficient installation of the vertical and horizontal pipeline sections of the vacuum system.

The vertical section of the pipeline must be assembled in such a way, that a drain is located opposite each floor, which is closed by a plug. This allows moving from one level of the building to another during a shift.

After reaching the required height of the pipeline vertical section, it is joined to the cyclone from one end, and a pipe branch or teejoint is installed on the other end to supply the pipeline into the room. After that, the horizontal branching of the main pipeline is mounted (Fig. 6). 

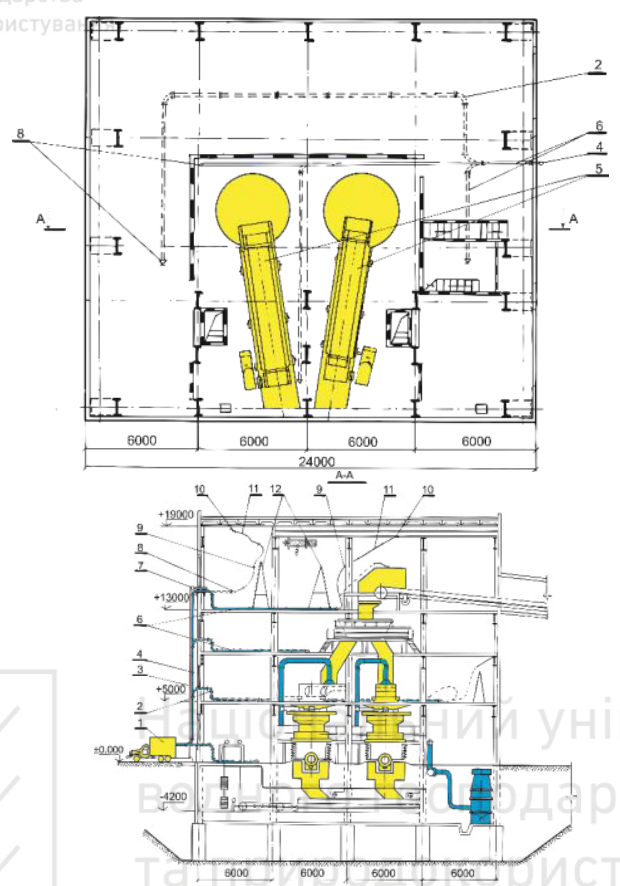

Fig. 6. Scheme of MADRI pipelines arrangement within the production premises: 1 - MADRI; 2 - pipeline elements (elbows, tee-joints, etc.); 3 - winch cable; 4 - vertical pipeline; 5 - loading conveyor; 6 - horizontal pipeline; 7 - block clamp; 8 - tapered adapter; 9 - flexible hose; 10 - nozzle; 11 - the handle; 12 ladders

The use of quick-disconnect coupling of two pipe sections allows installation of horizontal sections not over the entire area, but only for cleaning a specific section, using for this purpose the minimum required number of pipe segments and fittings. This allows significantly reduce the length of the pipeline system.

The vertical branches in certain places on the pipeline horizontal section (if necessary) are located. Their length depends on the height of the room. The connection of the flexible hose to the fittings located at the end of the vertical branches makes it possible to clean the upper area of the production room from the building structures, bridge cranes, crane runways, etc. There are fittings for connecting a flexible hose at the length of the pipeline horizontal section (Fig. 7). 


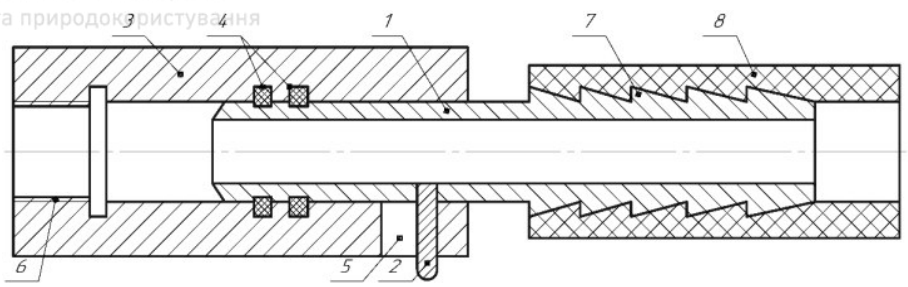

Fig. 7. Quick disconnect fitting for connecting a flexible hose: 1 - mouthpiece; 2 - pin; 3 - sleeve; 4 - rubber rings; 5 - locking slot; 8 - thread; 9 - ruff; 10 - flexible hose

The number of fittings is assumed such to allow all surfaces to be accessible when connecting a flexible hose.

\section{Conclusions}

The developed autonomous mobile dust-removal installation can autonomously move to the necessary cleaning object within the limits of the given enterprise, since the thrust booster and dust collecting devices are located in a mobile van, and the required remote system of pipelines with nozzles is mounted from separate units during the cleaning period. This reduces the overall length of the pipelines of the vacuum system and eliminates clogging of pipelines during long-term operation. The location of MADRI outside the object excludes the possibility of air recirculation in highly dusty premises. The absence of a stationary pipeline system, the ability to locate the installation at the most convenient points around the perimeter of an industrial facility, the speed of pipelines assembly and disassembly, the reuse of collected material and the high cleaning performance make it possible to solve the problem of dust collection with minimal costs. Thus, the use of mobile autonomous dust-removal installations at processing enterprises, together with the existing methods of dust suppression and dust collection, will allow "to keep clean" the production premises and to improve working conditions.

\section{Funding}

The research has no funding

\section{Disclosure Statement}

Authors have no competing financial, professional, or personal interests from other parties. 


\section{References}

1. Haponyuk O.Y., Honcharuk A.A., Lapyn A.P. Problemy funktsyonyrovanyya aspyratsyonnykh ustanovok y puty ykh sovershenstvovanyya [Problems of functioning of aspiration facilities and ways of their improvement]. Naukovi pratsi Odes'koyi natsional'noyi akademiyi kharchovykh tekhnolohiy.2014;46(1):201-204.

2. Golyshev A.M., Zadorozhniy S.I., Gerasimchuk A.V. et al. Obespecheniye effektivnykh rabochikh rezhimov aspiratsionnykh sistem fabrik okomkovaniya GOKov v usloviyakh dlitel'noy ekspluatatsii [Ensuring effective working conditions of the aspiration systems of the GOKs pelletizing plants under conditions of longterm operation]. Razrabotka rudnykh mestorozhdeniy.2007; 91:232-236. Russian

3. Sitnikov E.A. Nauka sobirat. Investitsii v nashe budushcheye. [Science to collect. Investing in our future]. Berg-Collegium: Mass analytical research and production journal. 2005;6:28-29. Russian

4. Sitnikov E.A. Nauka sobirat [Science to collect] Part II. Berg-Collegium: Mass analytical research and production journal. 2004;4:12-13. Russian

5. Ryazhin A.A. Pylevoy resurs. Rezervy effektivnosti ugolnykh TETS [Dust resource. Efficiency reserves of coal-fired power plants]. Berg-Collegium: Mass analytical research and production journal. 2005;2:21. Russian

6. Sitnikov E.A. Vakuumnyye tekhnologii Wieland Lufttechnik: ekonomiya ekologiya - effektivnost [Vacuum technologies Wieland Lufttechnik: savings ecology - efficiency]. Proceedings of the BALTIMIX-2004. Available at http://www.baltimix.ru/confer_archive/reports/doclad04/index.php

7. Kurnikov A.A., Kurnikov V.A. Pnevmaticheskaya pyleuborka tsekhov mashinostroitel'nykh zavodov [Pneumatic dust cleaning of machine-building factories]. Moscow: Mechanical Engineering; 1983. Russian

8. Department of Health and Human Services. Handbook for Dust Control in Mining.Rev. Ed. Fred N. Kissell). National Institute for Occupational Safety and Health: Pittsburgh Research Laboratory; 2003. Available at https://www.osmre.gov/resources/blasting/docs/MineGasesDust/2003NIOSHDust.pdf

9. Cecala A.B., O'Brien A.D., Schall J., et al. Dust control handbook for industrial minerals mining and processing. Pittsburgh, PA, Spokane, WA: Centers for disease control and prevention, National institute for occupational safety and health, office of mine safety and health research. 2012 (Report no. 9689). Available at https://www.spray.com/pdf/Dust_Control_Hanbook_RI9689.pdf

10. Borrmann M. Industrial vacuum systems for cement industry. Introduction and overview. Proceedings of AICCE22 - International Congress Center; 2017 Nov 15; Sharm el Sheikh: Wieland GmbH \& Co; 2017

11. Wen Nie, Wenle Wei, Peng Cai, et al. Simulation experiments on the controllability of dust diffusion by means of multi-radial vortex airflow. Advanced Powder Technology. 2018;29(3):835-847, DOI: 10.1016/j.apt.2017.12.027.

12. Wanxing Ren, Deming Wang, Qing Guo, et al. Application of foam technology for dust control in underground coal mine. International Journal of Mining Science and Technology. 2014;24(1):13-16. DOI: 10.1016/j.ijmst.2013.12.003. 